\section{Drs. Lidar and Livneh reply}

\section{To the Editor:}

We appreciate Dr. Kahn's insightful comments regarding the origin of the Ashkenazi Jews. Our objective, however, in describing the manifestations of FMF in our Ashkenazi cohort ${ }^{1}$, was a clinical one and so precise historical details were not abstracted. Rather, we followed the patients' own definition of themselves. In general, people tend to look back only a generation or 2 in describing their family's country of origin. That is, unless the family's earlier past is marked by a major historical event, such as a human or nature-induced catastrophe, that brought about an unexpected geographic shift. Such extraordinary circumstances are usually revealed when patients are questioned about their families' origin, albeit, some patients (Ashkenazi, North African, or Iraqi) might have been ethnically misdefined in our study. In this respect, we found that "self-defined" Ashkenazi patients with familial Mediterranean fever (FMF) form a unique group characterized by a milder clinical phenotype than that of North African or
Iraqi counterparts, but which, nonetheless, carries a profound risk of amyloidosis.

Our hope is that after reading our report, physicians will be more aware of the possibility of FMF in Ashkenazi subjects, encourage them to adhere to treatment with colchicine despite the milder attacks, and followup diligently for the development of renal complications.

MERAV LIDAR, MD; AVI LIVNEH, MD, Sheba Medical Center, Heller Institute of Medical Research, Tel Hashomer, Ramat Gan, 52621 Israel. Address correspondence to Dr. Lidar; E-mail: m-lidar@zahav.net.il

\section{REFERENCE}

1. Lidar M, Kedem R, Berkun Y, Langevitz P, Livneh A. Familial Mediterranean fever in Ashkenazi Jews: The mild end of the clinical spectrum. J Rheumatol 2010;37:422-5.

J Rheumatol 2010;37:10; doi:10.3899/jrheum.100742 